\section{Spontaneous bladder rupture in acute alcohol intoxication}

\section{Bahjat Barakat,' Raffaele Pezzilli, ${ }^{2}$ Riccardo Casadei ${ }^{3}$}

'Department of Emergency Medicine, S. Orsola-Malpighi Hospital; ${ }^{2}$ Department of Digestive Diseases and Internal Medicine, S. Orsola-Malpighi Hospital; ${ }^{3}$ Department of Surgery, S. OrsolaMalpighi Hospital, Bologna, Italy

\section{Abstract}

Spontaneous bladder rupture is a rare condition that can be followed by an acute alcohol intoxication and can be associated with significant morbidity and mortality. We report a case diagnosed in a alcoholic young male who was admitted to our emergency room for epigastric pain. The case demonstrates the difficulties with diagnosis and the need for physicians who work in an emergency room to be aware of this condition.

\section{Introduction}

It has been reported that spontaneous bladder rupture is a rare condition associated with significant morbidity and mortality ${ }^{1}$ and occurs in a high proportion of cases in alcoholics. ${ }^{2} \mathrm{We}$ report a case of spontaneous bladder rupture in a 45 year-old man that was admitted to our emergency room because of a persistent epigastric pain. This case further demonstrates the difficult diagnosis of this condition. A bedside ultrasound in an evaluation of patients with non specific abdominal pain can be of great help.

\section{Case Report}

A 45 year-old man was admitted to our Emergency Room for a persistent epigastric pain of about 4 hours duration. He was restless and he had a bad alcoholic breath. A part from a chronic high alcohol consumption his medical history was unremarkable and he did not take any medications. The abdomen was soft, non-distended with no palpable masses and no signs of cutaneous trauma ; he had a normal respiratory rate, a pulse rate of 100 beats per minute and body temperature of $37^{\circ} \mathrm{C}$. Arterial blood pressure was 120/70 mmHg. Electrocardiogram showed no alterations a part from an increased sinusal rhythm. Laboratory exami- nation revealed an increased number of white cell count $\left(13.8010^{3} \mathrm{~mm}^{3}\right)$, with normal red blood cells as well as normal platelet count. Hemoglobin and hematocrit were also within the normal range. Serum creatinine was slightly elevated $1.6 \mathrm{mg} / \mathrm{dL}$ (normal reference range 0.50-1.20) with normal blood urea nitrogen (BUN) levels $18.2 \mathrm{mmol} / \mathrm{L}$ (normal reference range 8-20); serum electrolytes concentration was also normal. Alcohol blood levels were of $221 \mathrm{mg} / \mathrm{L}$. Circulating hepatic and pancreatic markers of an acute damage were also normal. An ultrasound examination (Figure 1A) showed normal sized kidneys with no renal pelvis dilation, and with a normal appearance of the liver, the gallbladder, the pancreas and the spleen; however a free peritoneal fluid was noted (Figure 1B).

An abdominal CT scan was performed and this examination showed a large amount of abdominal fluid collection (Figure 2A), a normal liver with normal hepatic and portal veins (Figure 2B). The peritoneal fluid was drained by an ultrasonographic aspiration and biochemical analysis showed urine containing $113 \mathrm{mmo} / \mathrm{L}$ of sodium, $7.0 \mathrm{mmo} / \mathrm{L}$ potassium, $44.2 \mathrm{mmol} / \mathrm{L}$ of urea, and $5 \mathrm{~g} / \mathrm{L}$ of proteins. At laparoscopy carried out in emergency setting a large bladder intraperitoneal rupture was
Correspondence: Raffaele Pezzilli, Department of Digestive Diseases and Internal Medicine, Sant'Orsola-Malpighi Hospital, via Massarenti 9, 40138 Bologna, Italy.

Tel.+39.051.6364148 - Fax: +39.051 .6364148 .

E-mail: raffaele.pezzilli@aosp.bo.it

Conflict of interests: the authors declare no potential conflict of interests.

Key words: kidney failure, acute alcohol intoxication, bladder, spontaneous rupture.

Received for publication: 11 June 2013.

Revision received: 1 October 2013.

Accepted for publication: 1 October 2013.

This work is licensed under a Creative Commons Attribution 3.0 License (by-nc 3.0).

\section{(C)Copyright B. Barakat et al., 2014}

Licensee PAGEPress, Italy

Emergency Care Journal 2014; 10:1745

doi:10.4081/ecj.2014.1745

found and a laparotomy was performed to repair the damage; after repairing it, $10 \mathrm{~mL}$ of methylene blue was injected into the bladder to check the tightness of the suture and no

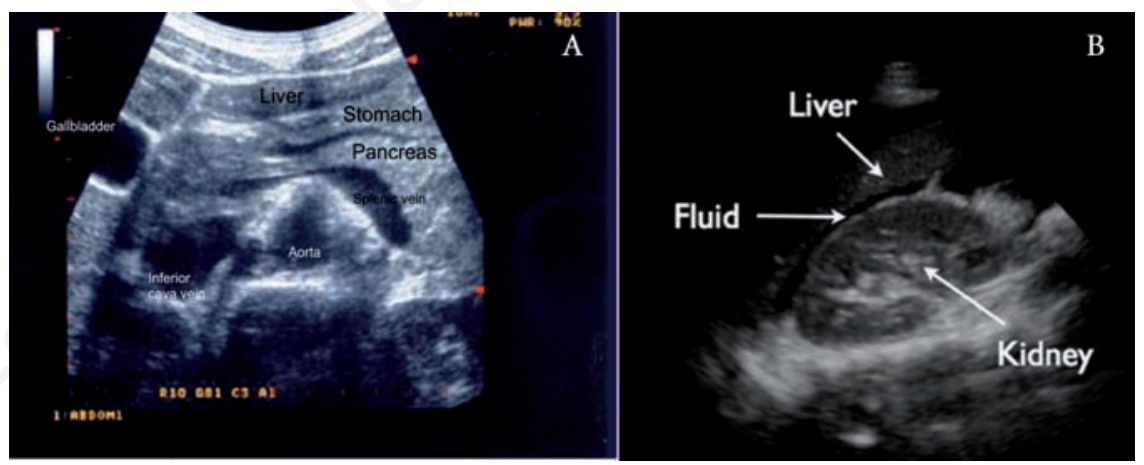

Figure 1. Ultrasound examination showing kidneys of normal size with no renal pelvis dilation, and normal appearance of liver, gallbladder, pancreas and spleen (A); a free peritoneal fluid can be noted $(B)$.
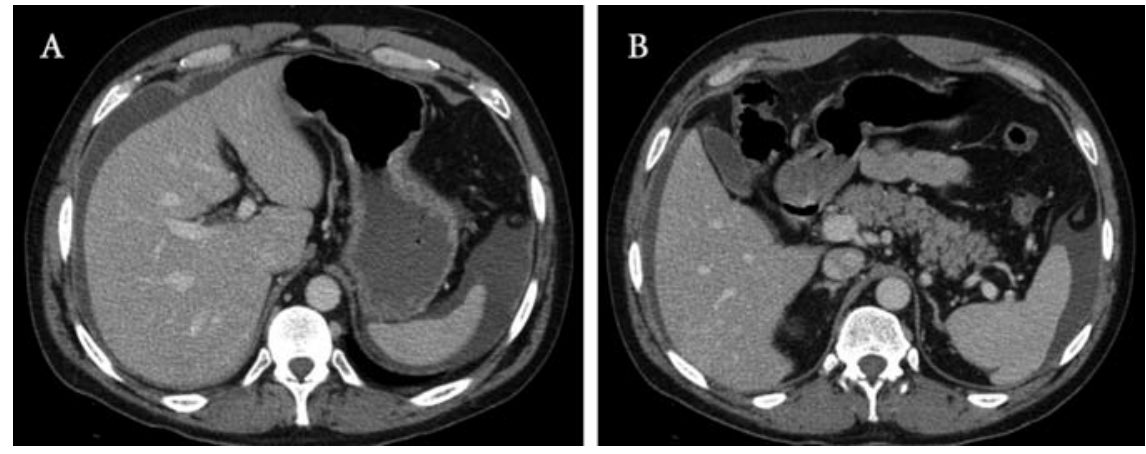

Figure 2. Abdominal CT scan showing a large amount of abdominal fluid (A) with normal liver, hepatic and portal veins $(B)$. 
spillage was noted. After one week, the urinary catheter was removed (Figure 3) and the patient was discharged in good general health.

\section{Discussion}

Acute and chronic alcohol consumption may cause several abdominal acute illnesses of a particular interest in an emergency situation. ${ }^{3}$ In addition, it is sometimes difficult to clinically evaluate these patients because of their abnormal behavior. ${ }^{4}$ Finally, the most common diseases in alcoholics are those involving the stomach and the pancreas and some abdominal emergencies are quite forgotten. One of these rare and generally unrecognized causes is represented by the bladder rupture. In 1959, Bastable et al. reported the highest amount of cases of spontaneous bladder ruptures ${ }^{1}$ and the author underlined that several of these cases reported were bladder ruptures associated with alcohol abuse. Subsequently, a total of 25 cases of spontaneous bladder rupture have been identified and these cases were associated with alcohol ${ }^{2,5,6}$ or drug abuse. ${ }^{7}$ In addition, this pathological condition was also described in decreased patients who regularly ingested

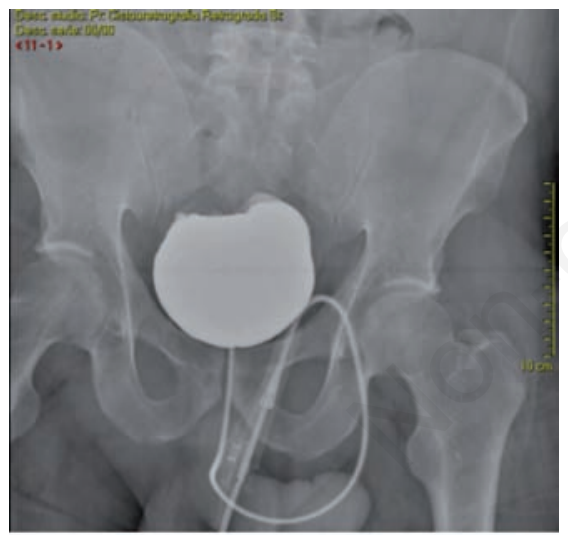

Figure 3. Retrograde cystography showing the complete repair of the bladder. large quantities of alcohol..$^{89}$ The hypothesis of pathogenesis of spontaneous rupture is believed to be due to a diuretic effect of alcohol, to impaired sensorium removing the cues for voiding causing bladder overdistension;,210 in addition, it has been hypothesized in women that the short length of the uretra and the less pronounced sphincter mechanism may lead to a leak between the bladder and the peritoneum rather than rupture. ${ }^{11}$

\section{Conclusions}

The early recognition of this illness has improved the mortality rate of $50 \%^{1}$ and decreased it to $12 \% .^{12}$ The new imaging techniques have an important role in diagnosing spontaneous bladder rupture even if the confirmation of this disease is to this day done by surgical exploration in most cases $^{13}$ because the diagnosis based on the early signs and symptoms may be of poor diagnostic significance: patients commonly present with lower abdominal pain, or inability to urinate or have hematuria. However, in our case the pain was localized in epigastrium leading to a more difficult diagnosis of intraperitoneal spontaneous bladder rapture and the patient had no hematuria. Physical examination is also unspecific because patients may have abdominal distension with signs of abdominal fluid collection. Aspiration and biochemical analysis of the abdominal fluid demonstrated a liquid similar to the urine, as in our case, it could be useful for the physicians to be aware of this disease. The repair of the intraperitoneal bladder rupture is surgical whereas extraperitoneal rupture is conservative by using ureteral catheterization. ${ }^{14}$

\section{References}

1. Bastable JR, De Jode LR, Warren RP. Spontaneous rupture of the bladder. Brit $\mathrm{J}$ Urol 1959;31:78-86.

2. Evans RA, Reece RW, Smith MJ.
Idiopathic rupture of the bladder. $\mathrm{J}$ Urology 1976;116:565-7.

3. Cargiulo T. Understanding the health impact of alcohol dependence. Am J Health-Syst Ph 2007;64(Suppl.3):5-11.

4. Li TK, McBride WJ. Pharmacogenetic models of alcoholism. Clin Neurosci 1995;3:182-8.

5. Christensen JB, Wara P, Hillstøm C. Spontaneous rupture of the urine bladder. Report of three cases. Scand J Urol Nephrol 1986;20:73-4.

6. Munshi IA, Hong JJ, Mueller CM, Barie PS. Spontaneous rupture of the urinary bladder in the alcoholic patient. J Trauma 1999;46:1133-4.

7. Marshall GA, Dixon CM, McAninch JW. Substance abuse-related spontaneous bladder rupture: report of 2 cases and review of the literature. J Urology 1991; 145:135-7.

8. Haddad FS, Wattle TL. Spontaneous intraperitoneal rupture of the bladder. Urol Int 1987;42:467-9.

9. Herd AM, Crofts NG, Lee LM, et al. Isolated bladder rupture after minor trauma in a patient with alcohol intoxication. J Emerg Med 1994;12:409-11.

10. Oliver JA, Taguchi Y. Rupture of the full bladder. Brit J Urol 1964;36:524-5.

11. Dooldeniya MD, Khafagy R, Mashaly H, et al. Lower abdominal pain in women after binge drinking. Brit Med J 2007;10:992-3.

12. Festini G, Gregorutti S, Reina G, Bellis GB. Isolated intraperitoneal bladder rupture in patients with alcohol intoxication and minor abdominal trauma. Ann Emerg Med 1991;20:1371-2.

13. Daignault MC, Saul T, Lewiss RE. Bedside ultrasound diagnosis of atraumatic bladder rupture in an alcohol-intoxicated patient: a case report. Crit Ultrasound J 2012;4:9.

14. Fu CY, Shih CH, Chang PY, et al. Conservative treatment of concomitant extraperitoneal bladder rupture and intrabladder blood clot formation: case report of application of ureteral catheterization. CUAJ-Can Urol Assoc 2012;6:2568. 